\title{
Dopamine D1 sensitivity in the prefrontal cortex predicts general cognitive abilities and is modulated by working memory training
}

\author{
Christopher Wass, Alessandro Pizzo, Bruno Sauce, Yushi Kawasumi, Tudor Sturzoiu, \\ Fred Ree, Tim Otto, and Louis D. Matzel ${ }^{1}$ \\ Department of Psychology, Rutgers University, Piscataway, New Jersey 08854, USA
}

\begin{abstract}
A common source of variance (i.e., "general intelligence") underlies an individual's performance across diverse tests of cognitive ability, and evidence indicates that the processing efficacy of working memory may serve as one such source of common variance. One component of working memory, selective attention, has been reported to co-vary with general intelligence, and dopamine D1 signaling in prefrontal cortex can modulate attentional abilities. Based on their aggregate performance across five diverse tests of learning, here we characterized the general cognitive ability (GCA) of CD-1 outbred mice. In response to a D1 agonist (SKF82958, $1 \mathrm{mg} / \mathrm{kg}$ ), we then assessed the relationship between GCA and activation of D1 receptor (DIR)-containing neurons in the prelimbic region of the medial prefrontal cortex, the agranular insular cortex, and the dorsomedial striatum. Increased activation of DIR-containing neurons in the prelimbic cortex (but not the agranular insular cortex or dorsomedial striatum) was observed in animals of high GCA relative to those of low GCA (quantified by c-Fos activation in response to the Dl agonist). However, a Western blot analysis revealed no differences in the density of DIRs in the prelimbic cortex between animals of high and low GCA. Last, it was observed that working memory training promoted an increase in animals' GCA and enhanced DIR-mediated neuronal activation in the prelimbic cortex. These results suggest that the sensitivity (but not density) of DIRs in the prelimbic cortex may both regulate GCA and be a target for working memory training.
\end{abstract}

Working memory and general intelligence are highly co-regulated (Engle et al. 1999; Conway et al. 2003; Colom et al. 2004), but the mechanisms that underlie this co-regulation have been difficult to assess in humans (Jensen 1998; Deary et al. 2009, 2010). Much like humans, the efficacy of an animal's working memory is correlated with, and may be a causal determinant of, general cognitive abilities (GCAs) (Kolata et al. 2007; Light et al. 2010; Matzel et al. 2011). Here we assessed whether innate GCA (as determined by an animal's aggregate performance across a diverse set of five learning tasks) and the beneficial influence of working memory training (WMT) on GCA shared a common substrate and target.

Imaging studies of humans have determined that the dorsolateral prefrontal cortex (dIPFC), as well as the parietal cortex, are engaged during working memory based tasks with a high dependence on selective attention (Rowe et al. 2000; Gray et al. 2003; Jung and Haier 2007; Barbey et al. 2013a,b), and it has been asserted that D1 activity levels in the dIPFC and D2 activity levels in the parietal cortex may play a role in modulating the relationship between working memory performance and intelligence (Aalto et al. 2005; Colom et al. 2007; Jung and Haier 2007; McNab et al. 2009; Barbey et al. 2013a). Furthermore, it has been suggested that working memory training (with high attentional demands) can positively impact an individual's performance on tests of fluid intelligence (Jaeggi et al. 2008; Tang and Posner 2009; Buschkuehl and Jaeggi 2010), and can produce functional changes in D1 dopaminergic binding in the prefrontal cortex (Olesen et al. 2004; McNab et al. 2009; Fischer et al. 2010). Although the interpretation

\section{${ }^{1}$ Corresponding author}

E-mail matzel@rci.rutgers.edu

Article is online at http://www.learnmem.org/cgi/doi/10.1101/lm.031971.113. of "working memory training" studies is highly controversial (Chooi and Thompson 2012; Shipstead et al. 2012; Redick et al. 2013), we have repeatedly observed that training procedures that tax working memory capacity and selective attention reliably improve the attentional performance of mice (Light et al. 2010; Matzel et al. 2011), and this facilitation of attention can promote performance on at least some of the tests that comprise our learning battery (see below).

Research using nonhuman animals has suggested that the medial prefrontal cortex (mPFC) in rodents may be homologous to the dorsolateral prefrontal cortex in humans (Lidow et al. 2003; Uylings et al. 2003; Kellendonk et al. 2006). The mPFC in rodents consists of three subregions, the anterior cingulate cortex, prelimbic cortex, and the infralimbic cortex (Kahn and Muly 2011). Specifically, lesions to the prelimbic cortex have been shown to broadly impair working memory performance (Cai and Arnsten 1997; Delatour and Gisquet-Verrier 2000; Ragozzino et al. 2002a; Heidbreder and Groenewegen 2003; Di Pietro et al. 2004; Gisquet-Verrier and Delatour 2006), as well as performance on tests of attention (Muir et al. 1996; Delatour and Gisquet-Verrier 2000; Chudasama et al. 2003; Gisquet-Verrier and Delatour 2006). Relatedly, direct injections of a D1 agonist into the prelimbic cortex have been shown to enhance the performance of animals on working memory tasks (Cai and Arnsten 1997; Mizoguchi et al. 2000; Chudasama and Robbins 2004), as

(C) 2013 Wass et al. This article is distributed exclusively by Cold Spring Harbor Laboratory Press for the first 12 months after the full-issue publication date (see http://learnmem.cshlp.org/site/misc/terms.xhtml). After 12 months, it is available under a Creative Commons License (AttributionNonCommercial 3.0 Unported), as described at http://creativecommons. org/licenses/by-nc/3.0/. 
well as attention tasks (Granon et al. 2000; Chudasama and Robbins 2004; Paine et al. 2007, 2009). Conversely, D1 antagonists have been shown to impair an animal's performance on working memory and attention-based tasks (Sawaguchi and GoldmanRakic 1994; Granon et al. 2000). Similarly, the agranular insular cortex (an area of the lateral PFC) has also been implicated in the regulation of working memory (Puumala and Sirvio 1998; Ragozzino et al. 1998, 2002a; Chudasama et al. 2003; Chudasama and Robbins 2004). Lesion studies have shown that the agranular insular cortex is involved in modulating an animal's ability to perform olfactory working memory tasks (Schoenbaum et al. 2003; Di Pietro et al. 2004), possibly due to its role in processing the incentive value of rewards (Schoenbaum et al. 1998; Gallagher et al. 1999; Kesner and Gilbert 2007). Many would suggest that these impairments/improvements in working memory and attentional performance (functions that are typically referred to as executive functions in primates) would, indeed, show that rodents possess a prefrontal cortical area that is homologous to the dlPFC in humans (Lidow et al. 2003; Uylings et al. 2003; Kellendonk et al. 2006). However, it should be noted that some would argue that rodents do not possess a prefrontal cortical area that truly parallels the dlPFC of primates (Preuss 1995; Brown and Bowman 2002). It is, indeed, possible that rodents do not possess such an area that can fully encompass all functions regulated by the dIPFC of humans, but the evidence described above suggests that subregions of the rodent mPFC, the prelimbic cortex in particular, have the ability to modulate executive functions.

Previously, we have used RNA microarrays to examine 25,000 genes in the frontal cortex of genetically heterogeneous CD-1 mice that had been characterized for their GCA. Using conservative selection criterion, 10 genes were found to be up-regulated in animals with high GCA. Of those 10 genes, three (Darpp-32, Rgs9, and Drd1a) formed a functional dopaminergic cluster which has the potential to modulate the sensitivity of dopamine binding to the D1R (Kolata et al. 2010). In conjunction with the results described above, our microarray analysis suggests that the efficacy of D1 signaling in the prefrontal cortex may modulate an individual's working memory/attentional abilities, and differences in D1R-containing neurons activity levels may therefore serve as one (of potentially many) (Deary et al. 2009, 2010, 2012) determinants of general cognitive performance. To test this hypothesis, in Experiment 1 we examined the level of D1-mediated neuronal activation in animals that had been quantified for their GCA (i.e., aggregate performance across a diverse set of five learning tasks). Experiment 2 then assessed whether any differences in D1R-mediated neuronal activation were related to the density of D1Rs in the prelimbic cortex. Last, Experiment 3 assessed whether the implementation of working memory training (with a high selective attention load) affected the same dopaminergic signaling mechanisms that may innately regulate GCA.

\section{Results}

\section{Experiment 1: D1 sensitivity and general cognitive abilities}

Here we assessed 48 genetically heterogeneous CD-1 mice on a battery of five learning tasks designed to tax different sensory/motor and information-processing systems. Each animal's aggregate performance (i.e., rate of acquisition) across these five tests of learning served as an indicator of that animal's general cognitive ability (GCA). The performance of individual animals across all learning tasks was first analyzed with a principal component analysis. This is a variable reduction procedure that uses an orthogonal transformation to convert a set of independent observations (po- tentially correlated variables) into a set of uncorrelated variables (i.e., principal components). The principal component factor analysis of animals' performance on the five learning tasks (see Table 1) indicated that performance on all tasks loaded in a consistent direction under a primary factor (GCA factor). That factor (eigenvalue 1.79 ) accounted for $\sim 30 \%$ of the variance in performance of individual animals across all tasks. A secondary factor, with an eigenvalue of 1.34, was also extracted and accounted for $\sim 22 \%$ of the variance. However, performance variables did not load in a consistent direction on this factor, meaning that there was not a common source of variance influencing the animals' performance across all tasks. Since the focus of our study is understanding the mechanisms modulating GCAs, the secondary factory was not further considered. From the primary factor, GCA factor scores were calculated for each of the animals. A factor score is essentially an average $z$-score of an animal's performance on the five learning tasks, with each score weighted according to the individual task's loading on the primary (GCA) factor. Thus an animal's factor score is a quantification of that animal's relative position in the distribution of GCAs represented by this sample.

Once each animal's factor score was obtained (where higher factor scores = higher GCAs), we then compared the factor scores of the animals that received a D1 agonist to their c-Fos immunoreactive nuclei in the prelimbic cortex $\left(r_{(22)}=0.48, P<0.02\right)$ (Fig. $1 \mathrm{~A})$, agranular insular cortex $\left(r_{(22)}=0.29\right.$, n.s.) (Fig. 1B), and the dorsomedial striatum $\left(r_{(22)}=0.06\right.$, n.s.) (Fig. 1C). These results indicate that animals which have higher GCAs expressed an increased level of D1R-mediated neuronal activation in the prelimbic cortex. There was no significant correlation between factor scores and c-Fos immunoreactive nuclei for any of the above regions in the animals that were treated with saline: prelimbic cortex $\left(r_{(22)}=0.08\right.$, n.s. $)$, agranular insular cortex $\left(r_{(22)}=0.26\right.$, n.s. $)$, and the dorsomedial striatum $\left(r_{(22)}=0.1\right.$, n.s. $)$.

Groups of animals representing different GCAs were then compared based on their aggregate performance across all learning tasks. That is, the factor scores (of each individual) were ranked, and the top, middle, and bottom thirds of these ranked scores were used to construct groups of animals representing high, intermediate, and low GCAs. Marked differences in the average number of D1R-mediated c-Fos immunoreactive nuclei in the prelimbic cortex were observed in animals of high, intermediate, and low GCAs (representative slices provided in Fig. 2). The average number of c-Fos immunoreactive nuclei in the prelimbic cortex (see Fig. 3A) was then compared between groups using an ANOVA which revealed a main effect of group, $F_{(2,21)}=3.59, P<0.05$. An LSD post hoc analysis revealed a significant difference between animals of high GCA and low GCA in the prelimbic cortex, $P<$ 0.05 . No significant differences were observed between animals of different cognitive abilities in either the agranular insular cortex $\left(F_{(2,21)}=2.25\right.$, n.s. $)$ or the dorsomedial striatum $\left(F_{(2,21)}=1.12\right.$, n.s.) (Fig. 3B,C).

Table 1. Experiment 1's factor loadings from the principal components analysis $(n=48)$ for performance on the five learning tasks

\begin{tabular}{lc}
\hline & General cognitive ability factor \\
\hline Lashley III maze & 0.63 \\
Water maze & 0.56 \\
Passive avoidance & 0.54 \\
Fear conditioning & 0.58 \\
Odor discrimination & 0.18 \\
Eigenvalue & $\mathbf{1 . 7 9}$ \\
Variance explained & $\mathbf{0 . 3 0}$ \\
\hline
\end{tabular}


A

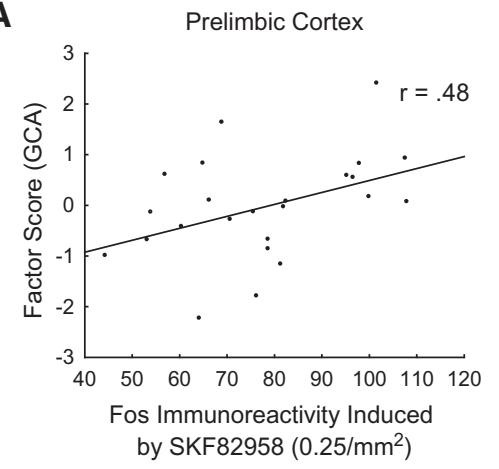

B

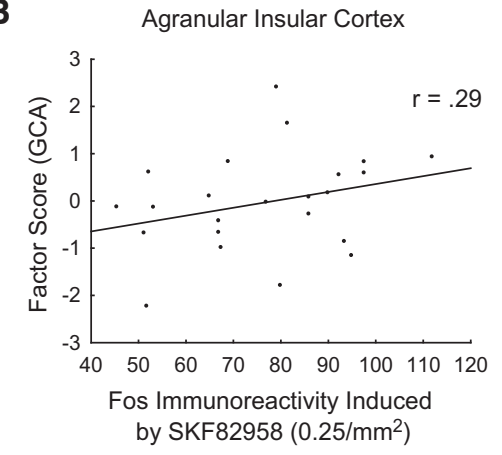

C

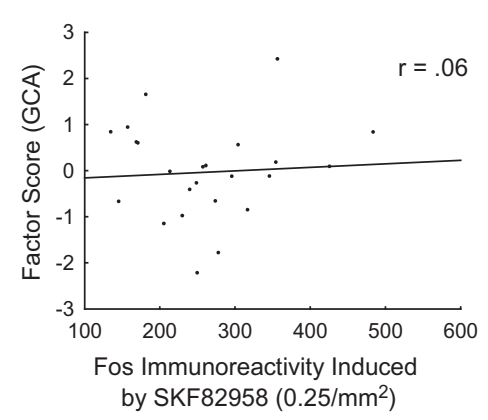

Figure 1. Number of Fos immunoreactive nuclei from individual animals following an administration of SKF82958. Factor scores for each animal were derived from a principal component analysis of all animals' performance on five learning tasks. These scores reflect each animal's aggregate performance across all five tasks (higher scores reflect higher GCAs). (A) A significant correlation $(P<0.05)$ was observed between animals' factor scores and the average number of Fos immunoreactive nuclei in the prelimbic cortex, indicating that animals with higher GCAs exhibit an increased expression of c-Fos after the administration of SKF82958 relative to animals of lower GCAs. No other comparisons were found to be significant when the number of c-Fos immunoreactive nuclei in the agranular insular cortex $(B)$ or the dorsomedial striatum (C) were compared to the animals' factor scores.

\section{Experiment 2: D1 receptor density and general cognitive abilities}

A sample of 32 CD-1 mice were assessed for their learning performance in the five learning tasks, which were once again subjected to a principal components analysis in order to derive each individual animal's factor score (indicative of GCA). A primary factor was extracted with an eigenvalue of 1.94 , which accounted for $32 \%$ of the variance in performance across the five tasks (Table 2). From the primary factor, factor scores were extracted to represent ani- mals' GCAs. A secondary factor was also extracted with an eigenvalue of 1.39 which accounted for $21 \%$ of the variance. Performance measures did not load in a consistent direction on this factor, indicating that this factor did not capture a common source of variance across all tasks. This factor will not be further considered. Since this experiment was intended to determine whether there was a differential level in the density of D1Rs in the prelimbic cortex between animals of high GCA compared to those of low GCA, eight animals with the highest GCAs and eight animals with the lowest GCAs were assessed for their levels of D1R protein by Western blotting procedures (Fig. 4A,B).

Once the density of $\mathrm{D} 1$ protein in the prelimbic cortex was quantified for each subject, we then assessed whether there were differences in the density of D1Rs between high GCA animals and low GCA animals. In order to accomplish this we averaged the density of the eight animals with the highest GCA $(13.3 \pm$ $\left.1.49_{\mathrm{SEM}}\right)$ and compared that to the average density of the eight animals with the lowest GCA $\left(13.68 \pm 2.09_{\text {SEM }}\right)$ using an independent samples $t$-test. Results indicate that there were no significant differences in the average density of each group, $t_{(14)}=-0.15$, n.s. (Fig. 4C). In addition to between-group comparisons (i.e., animals of high and low GCA), we also performed a simple correlation comparing D1R density level to factor scores, which again found no relationship between these two variables, $r_{(14)}=0.004$, n.s. These results indicate that the number of D1Rs does not differ between animals of high GCA and low GCA. Thus the increases in D1R-mediated neuronal activation observed in Experiment 1 were not likely the result of differential densities of D1 receptors.

\section{Experiment 3: Effect of working memory training on cognitive performance and D1 sensitivity}

It has been reported that the imposition of a working memory training regimen with a high demand on selective attention can promote an increase in the general cognitive performance of mice (Light et al. 2010; Matzel et al. 2011). Here we ascertained if working memory training targeted the same dopaminergic signaling mechanisms (D1R- containing neurons) that underlie innate cognitive abilities. One might expect such a modulation since receptor use is a critical determinant of rate of turnover, and turnover regulates sensitivity (Gygi et al. 1999; Ferguson 2001; Olesen et al.2004). Since D1Rs in prefrontal networks are preferentially active during the execution of working memory tasks, intense working memory training might reasonably be expected to promote an increased rate of turnover and hence sensitivity.

Here, animals received either working memory training (WMT, $n=30$ ), simple exposure to the training apparatus (EXP, $n=28$ ), or remained in their home cage (HOME, $n=26$ ). In order to ensure that animals of high GCA were not spuriously assigned into a single experimental group, the groups were created so that each group had a sample of animals with similar innate exploratory tendencies assessed by levels of exploration in an open field. As innate exploratory tendencies have been shown to be co-regulated with an animal's GCA, this served as a viable way to ensure that animals of similar GCAs were equally represented in each of our treatment groups (Matzel et al. 2006; Light et al. 2011). A subgroup of each of these groups (WMT, $n=14$; EXP, $n=14$; HOME, $n=12$ ) was subsequently assessed for performance across the battery of learning tasks (described below). As in the prior experiment, the acquisition performance of these animals across all learning tasks was first analyzed with a principal component analysis. This analysis extracted a primary factor (GCA factor) with an eigenvalue of 1.79 , which accounted for $36 \%$ of the variance in performance of individual animals across all tasks (see Table 3). A secondary factor was also extracted with an eigenvalue of 1.1 which accounted for $22 \%$ variance. However, 

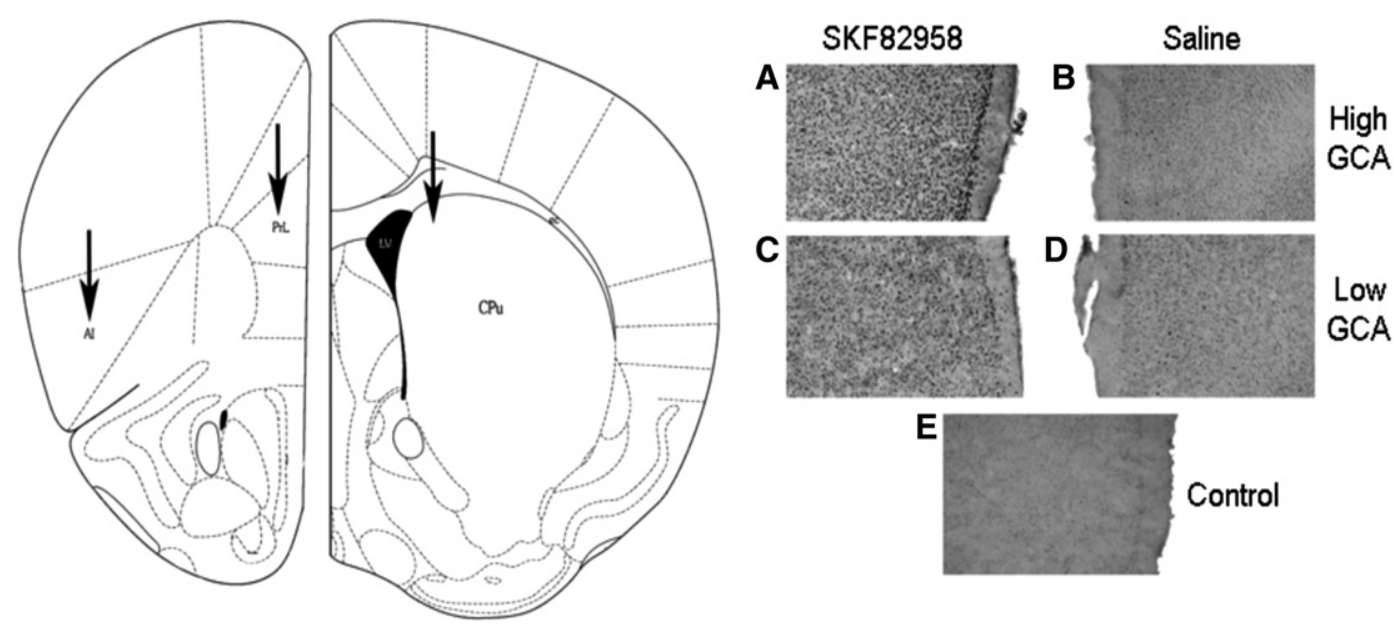

Figure 2. SKF82958-induced expression of c-Fos immunoreactivity in the prelimbic cortex of animals that have been characterized for their GCAs. (Left) Schematic illustration of the regions of interest (marked by an arrow) for the prelimbic cortex (center arrow), agranular insular cortex (in a cross-section taken $5.9 \mathrm{~mm}$ rostral to the interaural line, left arrow), and the dorsomedial striatum (located $4.48 \mathrm{~mm}$ rostral to the interaural line, right arrow). Coordinates conform to Franklin and Paxinos (1997). (Right) Marked differences in the expression of c-Fos immunoreactivity were detected in the prelimbic cortex 60 min after SKF82958 administration between animals of high GCAs ( $A$ ) when compared to animals of low GCAs (C). No measurable difference was observed between animals of high GCAs $(B)$ and low GCAs $(D)$ when administered saline. No c-Fos immunoreactivity was observed in a positive control $(E)$.

performance variables did not load in a consistent direction on this factor (indicating no common source of underlying variance), and so this factor will not be further considered. Factor scores were derived from the primary factor that represented the GCAs of individual animals. Factor scores were then segregated according to the treatment that the animals had previously received (i.e., WMT, EXP, HOME). When factor scores from the three treatment conditions were compared (see Fig. 5) a main effect of treatment was observed, $F_{(2,37)}=6.23, P<0.01$. Post hoc comparisons of factor scores revealed significant differences between the group that received working memory training (WMT) and the group that received simple exposure to the maze (EXP), $P<0.05$, and between group WMT and the HOME cage control condition, $P<$ 0.01. No significant difference was observed between groups EXP and HOME. These results indicate that $12 \mathrm{~d}$ of composite working memory training promoted an increase in the GCAs of treated animals.

Some of the animals received working memory training, simple exposure to the maze, or remained in their home cages, but underwent no behavioral testing in the learning battery (WMT, $n=$ 16; EXP, $n=14$; HOME, $n=14$ ). Half of the animals in each of these groups received an intraperitoneal injection of a D1 agonist (SKF82958) and the remaining half received a saline injection (resulting in a total of six groups). One-hour post-injection, levels of c-Fos immunoreactive nuclei were assessed in the prelimbic cortex, agranular insular cortex, and the dorsomedial striatum. Marked differences in the average number of c-Fos immunoreactive nuclei (in response to the D1 agonist) were observed in the prelimbic cortex between animals that received working memory training compared to animals which were either exposed to the maze or remained in their home cages throughout the experiment (Fig. 6A). The average number of c-Fos immunoreactive nuclei (induced by the $\mathrm{D} 1$ agonist) in the prelimbic cortex was compared between groups using an ANOVA which revealed a main effect of group, $F_{(2,19)}=5.11, P<0.05$. A Tukey HSD revealed a significant difference in D1 agonist-induced c-Fos immunoreactive nuclei between animals that had undergone working memory training and animals that had either simply been exposed to the apparatus $(P<$ $0.05)$ or that remained in their home cages $(P<0.05)$, and these comparisons are illustrated in Figure 6B. No significant differences were observed between any groups in the agranular insular cortex $F_{(2,19)}=.911$, n.s. (Fig. 6C), but there was a trend toward significance for a main effect of group in c-Fos immunoreactive nuclei in the dorsomedial striatum, $F_{(2,19)}=3.5, P=0.051$ (Fig. 6D). Further post hoc analysis revealed a trend toward a significant difference in the dorsomedial striatum between working memory trained animals and animals that were exposed to the apparatus for an equivalent amount of time $(P=0.075)$.

\section{Discussion}

The present experiments provide evidence that there is a differential level of D1R-mediated neuronal activation in the prelimbic cortex (the area in rodents that is thought to be homologous to the dIPFC in humans; Uylings et al. 2003) of animals that express high GCAs relative to animals of low GCAs. We had speculated that this difference in activation would arise as a consequence of a higher density of D1Rs, a result that would be consistent with our observation of elevated DRD1 mRNA levels in animals characterized as having high GCA (Kolata et al. 2010). However, no evidence for an increased density of D1Rs associated with higher cognitive abilities was observed here (Experiment 2). Nevertheless, it was observed (Experiment 3) that the imposition of a working memory training regimen promoted an increase in the neuronal activation of D1R-containing neurons in the prelimbic cortex, suggesting that training-induced differences in GCA may reflect a mechanism analogous to that which is associated with innate differences in GCA. It should be noted that we did not observe any differences in the number of Fos immunoreactive nuclei between the groups that received only a saline injection. That is, all saline-treated animals, regardless of whether they underwent working memory training or remained in their home cages, had similar basal levels of Fos immunoreactivity. One possible explanation for these results could be that since no cognitive demand was placed on the animals there was not a need for an increase in neuronal activation, an effect that is consistent with that reported in the human literature (Cohen et al. 1997). An 
A

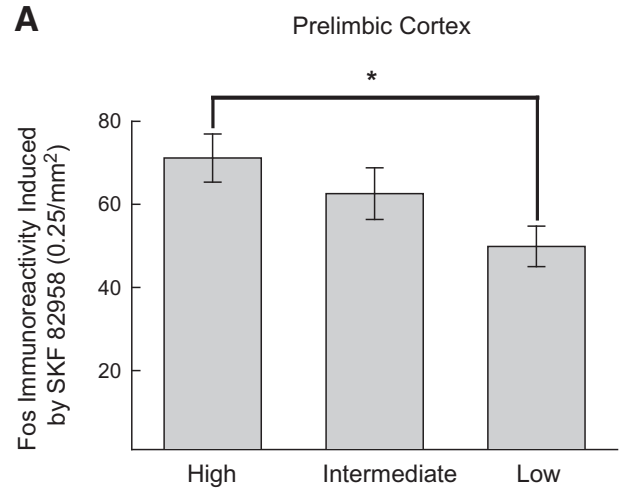

B

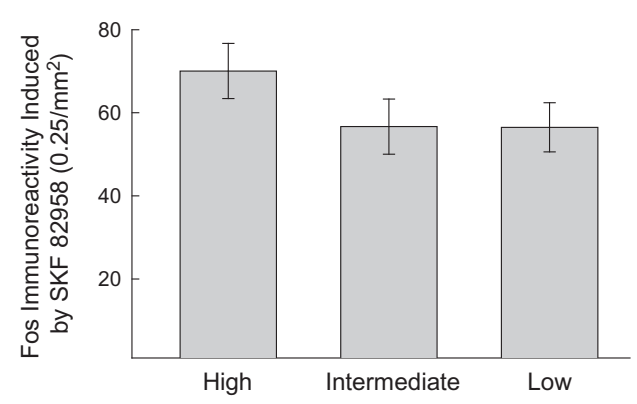

C

Dorsomedial Striatum

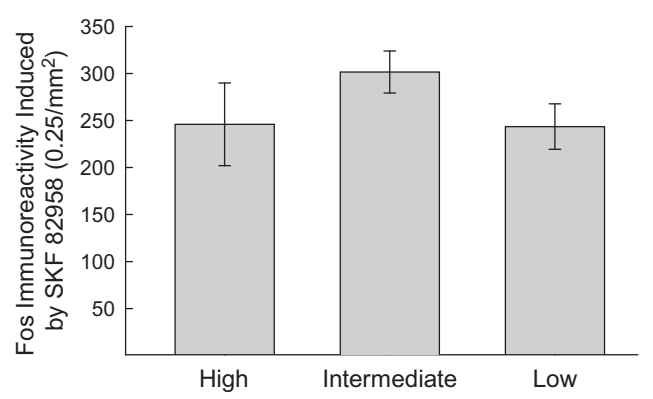

Figure 3. Exogenous application of SKF82958-induced c-Fos immunoreactive nuclei. Three groups of animals were formed based on the top, middle, and bottom third of the distribution of factor scores (reflective of GCAs) obtained from the principal component analysis of learning test performance (high factor scores = better general cognitive performance). Values are expressed as the mean \pm SEM. (A) Comparison of the mean number of c-Fos immunoreactive nuclei in the prelimbic cortex of animals that had been characterized as having high, intermediate, or low GCA revealed a significant difference between animals of high GCA and low GCA $(P<0.05)$. (B) Comparison of the mean number of $\mathrm{C}$-Fos immunoreactive nuclei in the agranular insular cortex of animals characterized for their GCA; no significant differences were observed. (C) No significant difference between groups was observed when the mean number of Fos immunoreactive nuclei in the dorsomedial striatum was compared.

increase in basal activity (as would be reflected in elevated Fos immunoreactivity) may be disadvantageous owing to the necessary energy consumption relative to reserving that activity for times of use (e.g., a cognitive demand upon stimulation of the D1 receptor). Thus, the administration of the D1 agonist (which simulates a cognitive demand) might result in an increase in neuronal excitability in the group that underwent working memory training compared to the groups that did not receive that training. These results extend the results obtained with humans showing that working memory training designed to heavily tax selective attention produces a functional change in dopaminergic binding in the dorsolateral prefrontal cortex (McNab et al. 2009), and facilitates the execution of behaviors that in aggregate are indicative of fluid intelligence (for review, see Buschkuehl and Jaeggi 2010).

The question of whether or not increases in mRNA levels should correlate with protein expression has been a central concern in the field of biology. In some instances, mRNA levels correlate highly with levels of protein expression (Futcher 1999), whereas in other cases, no correlation exists between the two (Gygi et al. 1999). The central supposition that DNA is transcribed into RNA and directly determines protein levels presumes that this transcription occurs independently of other rate-limiting factors. Although the results of mRNA analyses aid in the elucidation of how specific phenotypes may manifest, a myriad of factors mediating these processes need to be taken into account since an increase in mRNA simply increases the likelihood that the protein target will be differentially expressed. Factors such as protein halflife (rate of protein turnover), mutations in the mRNA causing them to be silenced (possibly through RNA interference or DNA methylation), or transporter variations can all determine protein levels (Greenbaum et al. 2003).

Our present experiments do not allow us to determine what factors impacted the level of D1R expression in high GCA animals, although an increase in the rate of receptor turnover may underlie the increase in DRD1 mRNA levels in high GCA animals that we have previously reported (Kolata et al. 2010). Importantly, an increase in receptor turnover rates would also correspond to an increase in the level of sensitivity of the D1R (Ferguson 2001). When a D1 agonist binds to the receptor it facilitates specific signaling cascades and, once that signaling cascade is initiated, the receptor is then removed from the membrane through sequestration. It has been long thought that sequestration's primary role was for receptor desensitization, but more recent evidence has shown that this process effectively promotes receptor re-sensitization which positively regulates receptor signaling (Ferguson 2001; Pierce et al. 2002). Therefore an enhanced rate of receptor turnover would enhance neuronal signaling. That increase in a neuron's signaling potential may underlie the increase in neuronal activity observed in animals of high GCA compared to those of low GCA.

Simulations of prefrontal cortex firing patterns have led to the hypothesis that D1 modulation of the prefrontal cortex implements a gating function that serves to regulate the maintenance of information in active memory in order to protect the memory from interference (i.e., focusing attention on task-relevant information). This attentional gating feature is thought to be regulated by top-down processing mechanisms. According to this model, D1Rs in the prefrontal cortex underlie the maintenance of relevant information by increasing the tonic activity (via increasing the

Table 2. Experiment 2's factor loading from the principal component analysis $(n=32)$ for performance on the five learning tasks

\begin{tabular}{lc} 
& General cognitive ability factor \\
\hline Lashley III maze & 0.75 \\
Water maze & 0.42 \\
Passive avoidance & 0.74 \\
Fear conditioning & 0.64 \\
Odor discrimination & 0.10 \\
Eigenvalue & $\mathbf{1 . 9 4}$ \\
Variance explained & $\mathbf{0 . 3 2}$ \\
\hline
\end{tabular}


A

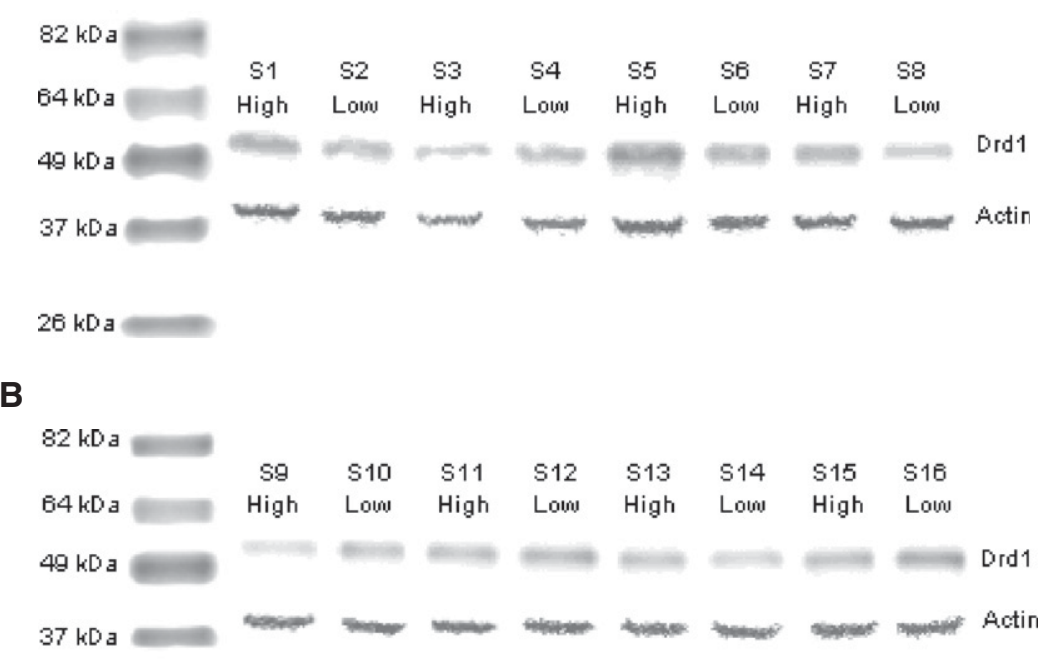

$26 \mathrm{kDa}$

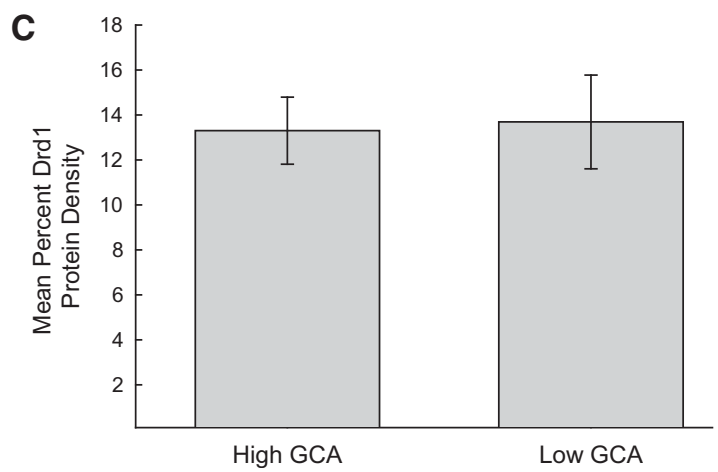

Figure 4. Eight animals characterized as having high GCAs and eight animals characterized as having low GCAs (taken from a total sample of 32 animals) were assayed for their levels of D1 receptor protein. Electrophoresis was performed across two gels $(A, B)$ in which animals of high GCA and low GCA alternated between gels as well as lanes within each gel. Twenty-five micrograms of protein from high GCA animals (S1, 3, 5, 7 in $A$; S9, 11, 13, 15 in $B$ ) and low GCA animals (S2, 4, 6, 8 in $A ; S 10,12,14,16$ in $B$ ) were loaded into each lane. Anti-Drd1 antibodies were then blotted against PVDF membranes and a single protein band was visualized at $\sim 52 \mathrm{kDA}$. (C) The mean \pm SEM density of D1 protein from eight animals with high GCAs was compared to the mean density of eight animals with low GCAs. An independent samples $t$-test revealed there was no significant difference in the mean density of D1 receptor protein levels between animals of high GCA compared to those of low GCA $(P>0.05)$.

gain) of dopaminergic neurons, thus protecting the memory from interference (Cohen et al. 2002; Costa 2007; Costa et al. 2007). This increase in gain promotes persistent neuronal firing in order to stabilize the actively stored memory. In order to then incorporate/update the contents of working memory to ensure that a behavior is guided toward a goal, dopamine D2 receptors are activated in the dorsomedial striatum which "opens the gates" by increasing the phasic activity of dopaminergic neurons and allowing the memory to be updated (Cohen et al. 2002; Wickens et al. 2007). This model has been supported by previous research showing that pharmacological blockade of D2 receptors or DA denervation in the dorsomedial striatum is crucial to the efficient shifting of behaviors (i.e., "cognitive flexibility") and important in facilitating corticostriatal plasticity (Centonze et al. 2001; O'Neill and Brown 2007).

This model of attentional regulation of information fits well with the present results in that animals with a higher level of GCAs exhibited more robust D1Rmediated neuronal activation. Such a characteristic would not only improve performance on a working memory task, but owing to the role of working memory in the execution of more basic learning tasks, would promote improvements in more general cognitive abilities, as working memory training did here.

The above hypothesis is consistent with the observation in Experiment 3 that animals which underwent extensive working memory training exhibited a consequent increase in D1R-mediated neuronal activation. Since working memory training required animals to actively maintain a memory of locations in the face of interfering external stimuli, that taxation (and its use of the D1R) may have increased the sensitivity of D1Rcontaining neurons. It is notable in this regard that implementation of a similar working memory training regimen also resulted in improved performance on specific tests of selective attention (Light et al. 2010; Matzel and Kolata 2010; Matzel et al. 2011).

One pathway that could incorporate the current findings with the model presented above may arise from the D1R's ability to inhibit protein phosphatase 1's (PP1) negative regulation of downstream proteins and kinases. PP1's inactivation results from the stimulation of D1Rs, which activate adenylate cyclase. Adenylate cyclase then converts adenosine triphosphate (ATP) to cyclic adenosine monophosphate (cAMP), which then phosphorylates protein kinase A (PKA) which in turn phosphorylates Darpp-32. When Darpp-32 is phosphorylated by PKA, it becomes a potent inhibitor of PP1 (Neve et al. 2004; Williams and Castner 2006). The suppression of PP1 leads to an increase in neuronal excitability which results in an increase in downstream proteins and kinases important for synaptic plasticity and the facilitation of learning and memory (Calabresi et al. 2000; Centonze et al. 2001; Genoux et al. 2002; Neve et al. 2004; Allen et al. 2006).

Table 3. Experiment 3's factor loading from the principal component analysis $(n=40)$ for performance on the five learning tasks

\begin{tabular}{lc}
\hline & General cognitive ability factor \\
\hline Lashley III maze & 0.48 \\
Water maze & 0.75 \\
Passive avoidance & 0.68 \\
Fear conditioning & 0.70 \\
Odor discrimination & 0.20 \\
Eigenvalue & $\mathbf{1 . 7 9}$ \\
Variance explained & $\mathbf{0 . 3 6}$ \\
\hline
\end{tabular}




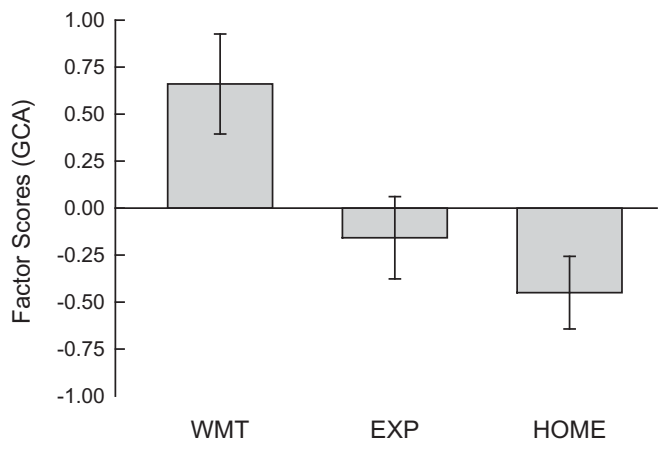

Figure 5. From principal components analysis of all learning tasks, GCAs (primary factor score) are plotted as a function of group wherein higher GCAs are indicated as higher factor score values. The imposition of a working memory training (group WMT) regimen promoted an enhancement of GCAs compared to animals that were exposed (EXP) to the training apparatus for an amount of time equivalent to the trained group, or remained in their home cages (HOME) throughout the experiment.

\section{Learning battery}

Learning, attentional, and reasoning abilities are co-regulated in CD-1 mice (Matzel et al. 2003; Kolata et al. 2007; Wass et al. 2012). Here GCA was assessed as aggregate performance of animals across a battery of five learning tasks (as first described in Matzel et al. 2003). These tasks were chosen for inclusion specifically because they represent different domains of learning, and are dependent on different sensory/motor and motivational systems. Likewise, these forms of learning are (varyingly) dependent on different neuroanatomical systems. Thus variance shared across all tasks is likely to represent those cognitive abilities that are shared across tasks, i.e., general cognitive ability. All of the animals were tested on the five tasks in the following order: Lashley III Maze, spatial water maze, passive avoidance, associative fear conditioning, and odor-guided discrimination. Three days of rest intervened between each successive task. For tasks utilizing food reinforcers, animals were food-deprived $48 \mathrm{~h}$ prior to training by allowing only $90 \mathrm{~min}$ of access to food within $2 \mathrm{~h}$ of the end of the light cycle. All of the procedures for the five tasks have been recently described in Wass et al. (2012); therefore, only brief descriptions of the tasks, as well as some of the neuroanatomical areas implicated in the processing of each task, will be discussed here.

Lashley III maze. In this task, animals were required to navigate from a starting location through a series of four interconnected alleys that D1Rs in the prefrontal cortex may play a role in the modulation of animals' GCAs through their regulation of the efficacy of selective attention (a component of working memory). Taking the current results together with the model presented above, it seems likely that the increase in neuronal activation could be due to a differential sensitivity of the D1R-containing neurons in animals of high GCA compared to animals of low GCA. An increased level of sensitivity would allow for an actively stored memory to be less prone to interference through a process of gain modulation. Although the current experiment cannot ascertain what the direct cause is of the increase in receptor sensitivity, it does suggest that behavioral training regimens and/or pharmacological manipulations could potentially serve to increase an individual's general intelligence.

\section{Materials and Methods}

\section{Experiment 1: D1 sensitivity and general cognitive abilities}

\section{Subjects}

Forty-eight male CD-1 outbred mice were obtained from Harlan Laboratories (Indianapolis, IN) at 45-50 d of age, and weighed $\sim 25-30 \mathrm{~g}$. The subjects were singly housed in clear standard shoe box cages in a humidity- and temperaturecontrolled vivarium maintained on a 12-h light-dark cycle. To minimize differential stress responses exhibited by the animals due to experimenter handling, the animals were handled by an experimenter for $90 \mathrm{sec}$ a day, $5 \mathrm{~d}$ per wk, for a period of 2 wk prior to the start of behavioral testing.

A
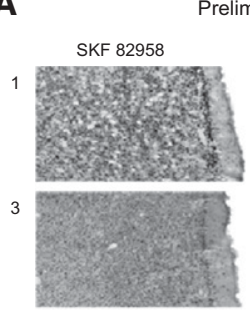

5

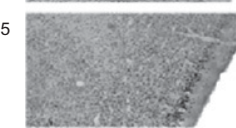

C
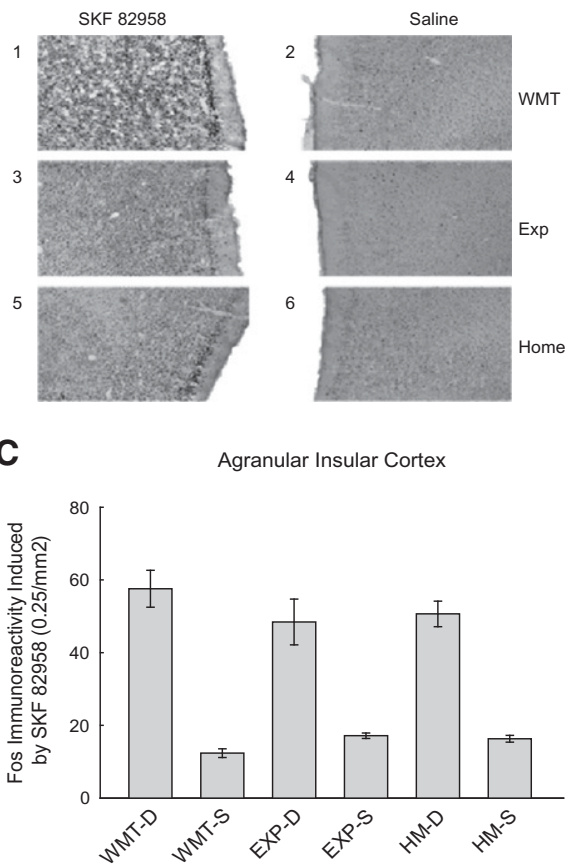

B

D

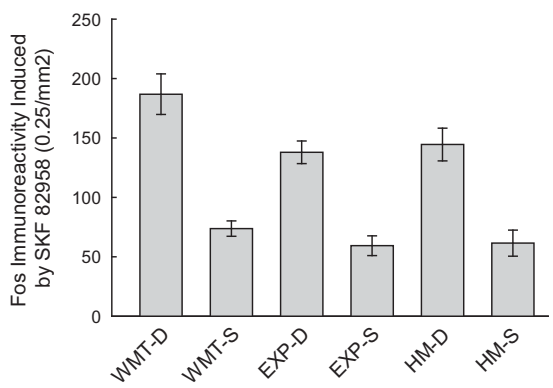

Figure 6. Differences in c-Fos immunoreactive nuclei were observed across treatment groups. $(A)$ Visualized c-Fos immunoreactivity in animals that had undergone working memory training (1), simple exposure to the apparatus (3), and those which remained in their home cages (5) 60 min after the administration of SKF82958. No differences were observed in either group of animals that received working memory training (2), exposure to the apparatus (4), or those which remained in the home cages (6) 60 min after the administration of saline. (B) Mean \pm SEM number of c-Fos immunoreactive nuclei expressed in the prelimbic cortex of animals that have been segregated into groups which received working memory training (WMT), exposure to the apparatus (EXP), or remained in their home cages (HM). Groups labeled with " $\mathrm{D}$ " following their respective grouping received an administration of SKF82958 $(1 \mathrm{mg} / \mathrm{kg})$, whereas groups labeled with "S" received saline. Post hoc analysis revealed a significant difference in D1 agonist induced c-Fos immunoreactivity between animals that have undergone working memory training and animals that had been exposed to the apparatus for an equivalent amount of time $(P<0.05)$ as well as animals that remained in the home cages $(P<0.05)$. No significant differences in D1 agonist induced c-Fos immunoreactivity were observed between groups in the agranular insular cortex $(C)$ or the dorsomedial striatum $(D)$. 
in order to receive a positive reinforcer located in a goal box connected to the fourth alley. In order to successfully traverse this maze without making errors (wrong turns which would result in a dead end or backtracking to a previously visited alley), the animal must utilize egocentric navigation (remembering a sequence of right or left turns). Some of the neuroanatomical areas thought to be involved in mediating learning in this task are the anterior cingulate cortex (Kesner et al. 1989; Kolb et al. 1994), prelimbic cortex (Kesner et al. 1989), and the dorsolateral striatum (De et al. 2005; Palencia and Ragozzino 2005).

Spatial water maze. In this task, an animal was immersed in a pool of opaque water in which it must locate a submerged platform. The performance of animals improved across trials (indicated by a reduction in path lengths and latencies to locate the platform) despite starting from multiple locations. Such a procedure mitigates the use of egocentric navigation and promotes the use of allocentric navigation (i.e., using stable extramaze cues in order to discern the location of the submerged platform). Neuroanatomical areas thought to be involved in modulating performance in this task include the hippocampus (Save and Poucet 2000), dorsomedial striatum (Ragozzino et al. 2002b), prelimbic cortex (Granon and Poucet 1995) and ventral striatum (De et al. 2005).

Passive avoidance. Passive avoidance is an operant conditioning task where an animal learns to suppress movement in order to avoid an aversive stimulus. This "passive" response is exemplified in step-down avoidance procedures where an animal is placed on an elevated platform and upon stepping off of that platform to a lower platform, it encounters an aversive noise/light compound stimulus. Here the latency for an animal to first step down (pre-training latency) from the elevated platform (which resulted in the presentation of the compound stimulus) was recorded. The animal was then confined to the "safe" elevated platform for a period of $4 \mathrm{~min}$. After the 4-min confinement period had elapsed, the latency of the animal to once again step down to the lower platform was recorded (post-training latency). The ratio of post-training to pre-training step-down latency was computed for each animal and served as an index of learning. The neuroanatomical areas thought to be involved in modulating learning during this task are the prelimbic cortex (Jinks and McGregor 1997), infralimbic cortex (Heidbreder and Groenewegen 2003), amygdala (Dunn and Everitt 1988), and the hippocampus (Wang and Cai 2008).

Associative fear conditioning. In this task, animals were required to learn the association between the presentation of a 20 -sec tone (CS) that predicted the onset of a foot shock (US). Freezing behavior to the CS was quantified "offline" from video recordings, where time spent freezing $20 \mathrm{sec}$ prior to the onset of the CS (in order to establish a criterion for baseline freezing) was recorded and subtracted from the time spent freezing during the CS presentation. Neuroanatomical areas thought to be involved in modulating learning during this task include the anterior cingulate cortex (Tang et al. 2005), amygdala, perirhinal cortex (Maren 2001), prelimbic cortex (Morgan and LeDoux 1995), and the infralimbic cortex (Milad and Quirk 2002).

Odor-guided discrimination. Rodents rapidly learn to use odors to guide appetitively reinforced behaviors. In this task animals learned to navigate a square field in which unique odor-marked (e.g., almond, mint, lemon) cue food cups were located in three corners. Although food was present in each cup, it was only accessible in the cup marked with the mint odorant. To begin a trial, an animal was placed in the empty corner of the field after which it was allowed to freely navigate the maze until it collected the accessible food reinforcer (marked by the mint odorant). On subsequent trials the location of the food cups varied across the four corners, but the reinforcers location always remained with the mint odor. An error was recorded anytime the animal made contact with an incorrect food cup, or its snout crossed a plane parallel to the perimeter of the food cup. Neuroanatomical areas thought to be involved in modulating learning in this task include the agranular insular cortex (Schoenbaum et al. 2003), olfactory bulb (Gheusi et al. 2000), prelimbic cortex (Tronel and Sara 2002), and the piriform cortex (Wilson 2003).

\section{c-Fos immunohistochemistry}

Two weeks after the completion of the learning battery, the subjects were subdivided into two groups with equal representation of animals exhibiting high GCA and low GCA (see Results). One of these groups received intraperitoneal injections $(1 \mathrm{mg} / \mathrm{kg})$ of a full D1 agonist, SKF82958 (Chloro-APB-hydrobromide), and the other received $0.09 \%$ saline solution. Sixty minutes after injections, the subjects were deeply anesthetized with Nembutal (150 mg.kg, i.p.) and perfused transcardially with a $4 \%$ paraformaldehyde solution. The brains were then extracted and allowed to post-fix for a 12 -h period in $4 \%$ paraformaldehyde. After the 12 -h post-fixation period the brains were transferred to a $30 \%$ sucrose solution (in $0.05 \mathrm{M}$ KPBS). The brains were then sectioned in a $1: 3$ series at $30-\mu \mathrm{m}$ sections on a freezing microtome (Thermo Scientific HM 525) and stored in a cryoprotectant at $4^{\circ} \mathrm{C}$ until ready to be stained.

Free-floating sections were washed five times for $5 \mathrm{~min}$ in $0.05 \mathrm{M} \mathrm{KPBS}$ ( $\mathrm{pH}$ 7.4) and blocked for endogenous peroxidase binding activity in $1 \% \mathrm{H}_{2} \mathrm{O}_{2}$ for a period of $30 \mathrm{~min}$. Following a series of five washes, the sections were incubated in rabbit anti-Fos antiserum (CalBiochem Ab-5, 1:15,000) diluted in $0.4 \%$ Triton-X, 1\% bovine serum albumin, in KPBS for $48 \mathrm{~h}$. After a series of five 10-min washes, the sections were incubated for $2 \mathrm{~h}$ with biotinylated goat anti-rabbit IgG (1:500, Vector Laboratories, Burlingham, CA) in KPBS, 4\% Triton-X at room temperature. An avidin-biotin peroxidase procedure (Vectastain Elite ABC Kit, Vector Laboratories) with 3,3'-diaminobenzidine (Sigma Fast DAB tablets D4293, Sigma) as the chromogen was then used to visualize c-Fos positive cells.

\section{Cell counts}

Sections of the prelimbic cortex and agranular insular cortex located $5.9 \mathrm{~mm}$ from the interaural line as well as the dorsomedial striatum located $4.48 \mathrm{~mm}$ from the interaural line were photographed using a Sony DFW SX900 Nikon Eclipse E400 digital camera. Cell counts were performed by an observer that was naive to the experimental conditions. cFos-immunoreactive nuclei were counted on the captured images using Image J software (NIH).

\section{Experiment 2: D1 receptor density and general cognitive abilities}

\section{Subjects}

A sample of 32 CD-1 outbred mice were obtained from Harlan Laboratories (Indianapolis, IN) at 45-50 d of age; their weight varied between 25 and $30 \mathrm{~g}$. Housing and maintenance conditions were identical to those previously described in Experiment 1.

\section{Learning battery}

All animals were subjected to the five-task learning battery in order to quantify their GCAs prior to analyzing D1 protein levels. The order in which the tasks were implemented was identical to that in Experiment 1 (see above). For a comprehensive review of the testing procedures see Wass et al. (2012).

\section{Drdla Western blot}

Two weeks following the completion of the learning battery, eight animals with the highest GCAs and eight animals with the lowest GCAs were sacrificed and their brains were rapidly extracted. Following brain extraction, their brains were placed in a brain blocker (Kopf Instruments) in order to ensure near identical 
sections were cut. Once the brain sections were cut, tissue punches corresponding to the prelimbic cortex were taken. Each tissue punch yielded $\sim 3 \mathrm{mg}$ of tissue.

Once the intended tissue samples were collected, the samples were suspended in ice-cold lysis buffer with a protease inhibitor cocktail (\#78430, Thermo Scientific). Protein extracts were then purified by sonication and centrifuged at $12,000 \mathrm{rpm}$ for $10 \mathrm{~min}$ at $4^{\circ} \mathrm{C}$. Supernatents were then extracted, flash frozen in liquid nitrogen, and stored at $-70^{\circ} \mathrm{C}$ until use. Protein concentrations were then determined in duplicates using a Bradford Assay Kit (Bio-Rad). Samples of $25 \mu \mathrm{g}$ of protein were separated by gel electrophoresis using 10\% TGX precast gels (\#456-1033, Bio-Rad) and blotted onto $0.4-\mu \mathrm{m}$ pore size PVDF membrane using the mini-Proteon tetra cell electrophoresis system (Bio-Rad). The membranes were then incubated with mouse anti-DRD1a monoclonal antibody (1:250, Chemicon International) and rabbit antiactin polyclonal antibody (1:5000, Abcam) in $20 \mathrm{mM}$ Tris HCL pH 7.5 containing $0.9 \% \mathrm{w} / \mathrm{v} \mathrm{NaCl}, 0.1 \% \mathrm{v} / \mathrm{v}$ Tween-20, and $5 \% \mathrm{w} / \mathrm{v}$ nonfat dry milk (Carnation) for $2 \mathrm{~h}$ at room temperature. The membrane was then washed three times for 10 min before being incubated in anti-mouse-IgG and anti-rabbit-IgG conjugated to horseradish peroxidase (1:500, Millipore). Protein bands were then detected using a chemiluminescent substrate ECL kit (\# 2650, Millipore) and visualized with a Bio-Rad Fluor-S multiimager and normalized to actin. Band densities were then analyzed using Image J software provided by NIH.

\section{Experiment 3: Effect of working memory training on cognitive performance and D1 sensitivity}

\section{Subjects}

Eighty-five CD-1 outbred mice were obtained from Harlan Laboratories (Indianapolis, IN) at $45-50 \mathrm{~d}$ of age and weighed between 25 and $30 \mathrm{~g}$. Housing and maintenance conditions were identical to those described in Experiment 1.

\section{Working memory training}

This experiment utilized a three-group design. One group received working memory training (WMT, $n=30$ ), one received an equivalent amount of time exposed to the training apparatus without being trained (EXP, $n=28$ ), and one remained in their home cages and received only an equivalent amount of handling and reinforcers (HOME, $n=26$ ). To ensure that a random selection of animals was assigned to each of the groups, we first assessed the animals' innate propensity for exploration in an open field (a behavior that tends to predict GCA). Once the animals' propensity for exploration was quantified, they were divided into three groups with similar exploratory tendencies constituting group WMT, EXP, and HOME.

A complete description of these procedures appears in Light et al. (2010). Briefly, mice in the WMT group were trained to asymptote on two distinct radial arm mazes (one black with walls around the center hub, one gray with no walls), where the animals collected food at the end of each of the eight arms. The mazes were located in the same room such that they shared common extramaze visual stimuli (geometric patterns comprised of small LED ["Christmas"] bulbs, pictures, and architectural details that can be used by the animal as search cues).

Each trial in each maze began with one piece of food at the end of each arm. Animals were initially trained on each maze individually. Trials (i.e., completion of one maze) were administered once per day (alternating the black and gray mazes across days), and this training was complete in $32 \mathrm{~d}$ (i.e., all animals received 16 trials in each maze). At the end of this training, performance of all animals had stabilized and all animals made at least six consecutive correct choices on the last two trials in each maze. At this point, animals continued training, but now received two trials a day, one in each maze (with a 4-h inter-trial interval). This training proceeded for $4 \mathrm{~d}$ (during which the order of testing in the two mazes alternated across days). Subsequent to this initial training (during which the animals had received a total of 20 trials in each maze), the animals then performed concurrently on both mazes once a day for $12 \mathrm{~d}$ (constituting working memory training). During this training, mice alternated choices in blocks of three in each maze (i.e., were allowed to find three pellets in the black maze, three pellets in the gray maze, three pellets in the black, three pellets in the gray, two pellets in the black, two pellets in the gray). This training required the animals to concurrently maintain a memory of the choices in each maze. This task has been asserted to have a high attentional demand, since the memory of previously visited arms is dependent on extramaze visual cues that are common to the two mazes (i.e., the mazes are located in a single room). Thus, this training taxed both the maintenance of information as well as working memory capacity and selective attention (see Matzel and Kolata [2010] for an expanded rationale).

During each of the training periods described above, subjects in the EXP group were placed in the apparatus for an amount of time that equaled matched animals in the WMT group. The EXP group also received reinforcers in the apparatus, but the pellets were not located at the end of each arm; rather, they were located at the beginning of each arm nearest the central hub so that working memory was not taxed (since the animal could see the food and would not have to actively maintain the locations that it had previously visited). This group ensured that the effects of working memory training were not solely due to the animals being exposed to a novel environment or the level of activity associated with the working memory training procedure.

\section{Learning battery}

A subgroup of animals that received working memory training $(n=14)$, exposure to the training apparatus $(n=14)$, or remained in their home cages $(n=12)$ was assessed for the animals' cognitive performance across the battery of five learning tasks in order to ensure that the training procedure effectively enhanced the GCA of animals that received training. The order the tasks were implemented was identical to that in Experiment 1 (see above).

\section{cFos immunohistochemistry}

Two weeks following the completion of the working memory training regimen, the three groups of animals that received no behavioral testing (WMT, $n=16$; EXP, $n=14$; HOME, $n=14$ ) were further subdivided in half (resulting in a total of six groups). Three groups received (via i.p. injection, $1 \mathrm{mg} / \mathrm{kg}$ ) the D1 agonist SKF82958 (Chloro-APB-Hydrobromide), and three received an injection of $0.09 \%$ saline. Further histological procedures/analyses for the expression of c-Fos were performed identically to those of Experiment 1.

\section{Acknowledgments}

This work was supported by the National Institute on Aging (AG022698), the Office of Naval Research (N000141210873), the Busch Foundation (to L.D.M.) and the National Science Foundation (IOS 0919159) to T.O.

\section{References}

Aalto S, Bruck A, Laine M, Nagren K, Rinne JO. 2005. Frontal and temporal dopamine release during working memory and attention tasks in healthy humans: A positron emission tomography study using the high-affinity dopamine D2 receptor ligand [11C]FLB 457. J Neurosci 25: $2471-2477$.

Allen PB, Zachariou V, Svenningsson P, Lepore AC, Centonze D, Costa C, Rossi S, Bender G, Chen G, Feng F, et al. 2006. Distinct roles for spinophilin and neurabin in dopamine-mediated plasticity. Neuroscience 140: 897-911.

Barbey AK, Colom R, Grafman J. 2013a. Dorsolateral prefrontal contributions to human intelligence. Neuropsychologia 51: 1361-1369. Barbey AK, Koenigs M, Grafman J. 2013b. Dorsolateral prefrontal contributions to human working memory. Cortex 49: 1195-1205.

Brown VJ, Bowman EM. 2002. Rodent models of prefrontal cortical function. Trends Neurosci 25: 340-343. 
Buschkuehl M, Jaeggi SM. 2010. Improving intelligence: A literature review. Swiss Med Wkly 140: 266-272.

Cai JX, Arnsten AF. 1997. Dose-dependent effects of the dopamine D1 receptor agonists A77636 or SKF81297 on spatial working memory in aged monkeys. J Pharmacol Exp Ther 283: 183-189.

Calabresi P, Gubellini P, Centonze D, Picconi B, Bernardi G, Chergui K, Svenningsson P, Feinberg AA, Greengard P. 2000. Dopamine and cAMP-regulated phosphoprotein $32 \mathrm{kDa}$ controls both striatal long-term depression and long-term potentiation, opposing forms of synaptic plasticity. J Neurosci 20: 8443-8451

Centonze D, Picconi B, Gubellini P, Bernardi G, Calabresi P. 2001. Dopaminergic control of synaptic plasticity in the dorsal striatum. Eur J Neurosci 13: 1071-1077.

Chooi WT, Thompson LA. 2012. Working memory training does not improve intelligence in healthy young adults. Intelligence 40: 531-542.

Chudasama Y, Robbins TW. 2004. Dopaminergic modulation of visual attention and working memory in the rodent prefrontal cortex. Neuropsychopharmacology 29: 1628-1636.

Chudasama Y, Passetti F, Rhodes SE, Lopian D, Desai A, Robbins TW. 2003. Dissociable aspects of performance on the 5 -choice serial reaction time task following lesions of the dorsal anterior cingulate, infralimbic and orbitofrontal cortex in the rat: Differential effects on selectivity, impulsivity and compulsivity. Behav Brain Res 146: $105-119$.

Cohen JD, Perlstein WM, Braver TS. 1997. Temporal dynamics of brain activation during a working memory task. Nature 386: 604-608.

Cohen JD, Braver TS, Brown JW. 2002. Computational perspectives on dopamine function in prefrontal cortex. Curr Opin Neurobiol 12: 223-229.

Colom R, Rebollo I, Palacios A, Juan-Espinosa M, Kyllonen PC. 2004. Working memory is (almost) perfectly predicted by g. Intelligence $\mathbf{3 2}$ : 277-296.

Colom R, Jung RE, Haier RJ. 2007. General intelligence and memory span: Evidence for a common neuroanatomic framework. Cogn Neuropsychol 24: $867-878$.

Conway AR, Kane MJ, Engle RW. 2003. Working memory capacity and its relation to general intelligence. Trends Cogn Sci 7: 547-552.

Costa RM. 2007. Plastic corticostriatal circuits for action learning: What's dopamine got to do with it? Ann N Y Acad Sci 1104: 172-191.

Costa RM, Gutierrez R, De Araujo IE, Coelho MR, Kloth AD, Gainetdinov RR, Caron MG, Nicolelis MA, Simon SA. 2007. Dopamine levels modulate the updating of tastant values. Genes Brain Behav 6: 314-320.

De LE, Oliverio A, Mele A. 2005. A study on the role of the dorsal striatum and the nucleus accumbens in allocentric and egocentric spatial memory consolidation. Learn Mem 12: 491-503.

Deary IJ, Johnson W, Houlihan LM. 2009. Genetic foundations of human intelligence. Hum Genet 126: 215-232.

Deary IJ, Penke L, Johnson W. 2010. The neuroscience of human intelligence differences. Nat Rev Neurosci 11: 201-211.

Deary IJ, Yang J, Davies G, Harris SE, Tenesa A, Liewald D, Luciano M, Lopez LM, Gow AJ, Corlie J, et al. 2012. Genetic contributions to stability and change in intelligence from childhood to old age. Nature 482: $212-215$.

Delatour B, Gisquet-Verrier P. 2000. Functional role of rat prelimbicinfralimbic cortices in spatial memory: Evidence for their involvement in attention and behavioural flexibility. Behav Brain Res 109: 113-128.

Di Pietro NC, Black YD, Green-Jordan K, Eichenbaum HB, Kantak KM. 2004. Complementary tasks to measure working memory in distinct prefrontal cortex subregions in rats. Behav Neurosci 118: 1042-1051.

Dunn LT, Everitt BJ. 1988. Double dissociations of the effects of amygdala and insular cortex lesions on conditioned taste aversion, passive avoidance, and neophobia in the rat using the excitotoxin ibotenic acid. Behav Neurosci 102: 3-23.

Engle RW, Tuholski SW, Laughlin JE, Conway AR. 1999. Working memory, short-term memory, and general fluid intelligence: A latent-variable approach. J Exp Psychol Gen 128: 309-331.

Ferguson SS. 2001. Evolving concepts in G protein-coupled receptor endocytosis: The role in receptor desensitization and signaling. Pharmacol Rev 53: $1-24$.

Fischer H, Nyberg L, Karlsson S, Karlsson P, Brehmer Y, Rieckmann A, MacDonald SWS, Farde L, Bäckman L. 2010. Simulating neurocognitive aging: Effects of a dopaminergic antagonist on brain activity during working memory. Biol Psychiatry 67: 575-580.

Franklin KBJ, Paxinos G. 1997. The mouse brain in stereotaxic coordinates. Elsevier, Cambridge.

Futcher B. 1999. Cell cycle synchronization. Methods Cell Sci 21: 79-86.

Gallagher M, McMahan RW, Schoenbaum G. 1999. Orbitofrontal cortex and representation of incentive value in associative learning. J Neurosci 19: $6610-6614$.
Genoux D, Haditsch U, Knobloch M, Michalon A, Storm D, Mansuy IM. 2002. Protein phosphatase 1 is a molecular constraint on learning and memory. Nature 418: 970-975.

Gheusi G, Cremer H, McLean H, Chazal G, Vincent JD, Lledo PM. 2000. Importance of newly generated neurons in the adult olfactory bulb for odor discrimination. Proc Natl Acad Sci 97: 1823-1828.

Gisquet-Verrier P, Delatour B. 2006. The role of the rat prelimbic/ infralimbic cortex in working memory: Not involved in the short-term maintenance but in monitoring and processing functions. Neuroscience 141: $585-596$.

Granon S, Poucet B. 1995. Medial prefrontal lesions in the rat and spatial navigation: Evidence for impaired planning. Behav Neurosci 109: $474-484$.

Granon S, Passetti F, Thomas KL, Dalley JW, Everitt BJ, Robbins TW. 2000. Enhanced and impaired attentional performance after infusion of D1 dopaminergic receptor agents into rat prefrontal cortex. J Neurosci 20: $1208-1215$

Gray JR, Chabris CF, Braver TS. 2003. Neural mechanisms of general fluid intelligence. Nat Neurosci 6: 316-322.

Greenbaum D, Colangelo C, Williams K, Gerstein M. 2003. Comparing protein abundance and mRNA expression levels on a genomic scale. Genome Biol 4: 117

Gygi SP, Rochon Y, Franza BR, Aebersold R. 1999. Correlation between protein and mRNA abundance in yeast. Mol Cell Biol 19: 1720-1730.

Heidbreder CA, Groenewegen HJ. 2003. The medial prefrontal cortex in the rat: Evidence for a dorso-ventral distinction based upon functional and anatomical characteristics. Neurosci Biobehav Rev 27: $555-579$.

Jaeggi SM, Buschkuehl M, Jonides J, Perrig WJ. 2008. Improving fluid intelligence with training on working memory. Proc Natl Acad Sci 105: 6829-6833.

Jensen AR. 1998. The g factor: The science of mental ability (human evolution, behavior, and intelligence). Praeger, New York.

Jinks AL, McGregor IS. 1997. Modulation of anxiety-related behaviours following lesions of the prelimbic or infralimbic cortex in the rat. Brain Res 772: 181-190.

Jung RE, Haier RJ. 2007. The Parieto-Frontal Integration Theory (P-FIT) of intelligence: Converging neuroimaging evidence. Behav Brain Sci 30: $135-154$.

Kahn ZU, Muly C. 2011. Molecular mechanisms of working memory. Behav Brain Res 219: 329-341.

Kellendonk C, Simpson EH, Polan J, Malleret G, Vronskaya S, Winiger V, Moore H, Kandel ER. 2006. Transient and selective overexpression of dopamine D2 receptors in the striatum causes persistent abnormalities in prefrontal cortex function. Neuron 49: 603-615.

Kesner RP, Gilbert PE. 2007. The role of the agranular insular cortex in anticipation of reward contrast. Neurobiol Learn Mem 88: 82-86.

Kesner RP, Farnsworth G, DiMattia BV. 1989. Double dissociation of egocentric and allocentric space following medial prefrontal and parietal cortex lesions in the rat. Behav Neurosci 103: 956-961.

Kolata S, Light K, Grossman HC, Hale G, Matzel LD. 2007. Selective attention is a primary determinant of the relationship between working memory and general learning ability in outbred mice. Learn Mem 14: $22-28$.

Kolata S, Light K, Wass CD, Colas-Zelin D, Roy D, Matzel LD. 2010. A dopaminergic gene cluster in the prefrontal cortex predicts performance indicative of general intelligence in genetically heterogeneous mice. PLoS One 5: e14036.

Kolb B, Buhrmann K, McDonald R, Sutherland RJ. 1994. Dissociation of the medial prefrontal, posterior parietal, and posterior temporal cortex for spatial navigation and recognition memory in the rat. Cereb Cortex 4: $664-680$.

Lidow M, Koh P, Arnsten A. 2003. D1 dopamine receptors in the mouse prefrontal cortex: Immunocytochemical and cognitive neuropharmacological analyses. Synapse 47: 101-108.

Light KR, Kolata S, Wass C, Denman-Brice A, Zagalsky R, Matzel LD. 2010. Working memory training promotes general cognitive abilities in genetically heterogeneous mice. Curr Biol 20: 777-782.

Light KR, Grossman H, Kolata S, Wass C, Matzel LD. 2011. General learning ability regulates exploration through its influence on rate of habituation. Behav Brain Res 223: 297-309.

Maren S. 2001. Neurobiology of Pavlovian fear conditioning. Annu Rev Neurosci 24: 897-931.

Matzel LD, Kolata S. 2010. Selective attention, working memory, and animal intelligence. Neurosci Biobehav Rev 34: 23-30.

Matzel LD, Han YR, Grossman H, Karnik MS, Patel D, Scott N, Specht SM, Ghandi CC. 2003. Individual differences in the expression of a "general" learning ability in mice. J Neurosci 23: 6423-6433.

Matzel LD, Townsend DA, Grossman H, Han YR, Hale G, Zappulla M, Light K, Kolata S. 2006. Exploration in outbred mice covaries with general learning abilities irrespective of stress reactivity, emotionality, and physical attributes. Neurobiol Learn Mem 86: 228-240. 
Matzel LD, Light KR, Wass C, Colas-Zelin D, Denman-Brice A, Waddel AC, Kolata S. 2011. Longitudinal attentional engagement rescues mice from age-related cognitive declines and cognitive inflexibility. Learn Mem 18: 345-356.

McNab F, Varrone A, Farde L, Jucaite A, Bystritsky P, Forssberg H, Klingberg T. 2009. Changes in cortical dopamine D1 receptor binding associated with cognitive training. Science 323: 800-802.

Milad MR, Quirk GJ. 2002. Neurons in medial prefrontal cortex signal memory for fear extinction. Nature 420: 70-74.

Mizoguchi K, Yuzurihara M, Ishige A, Sasaki H, Chui DH, Tabira T. 2000. Chronic stress induces impairment of spatial working memory because of prefrontal dopaminergic dysfunction. J Neurosci 20: 1568-1574.

Morgan MA, LeDoux JE. 1995. Differential contribution of dorsal and ventral medial prefrontal cortex to the acquisition and extinction of conditioned fears in rats. Behav Neurosci 109: 681-688.

Muir JL, Everitt BJ, Robbins TW. 1996. The cerebral cortex of the rat and visual attentional function: Dissociable effects of mediofrontal, cingulate, anterior dorsolateral, and parietal cortex lesions on a five-choice serial reaction time task. Cereb Cortex 6: 470-481.

Neve KA, Seamans JK, Trantham-Davidson H. 2004. Dopamine receptor signaling. J Recept Signal Transduct Res 24: 165-205.

Olesen PJ, Westerberg H, Klingberg T. 2004. Increased prefrontal and parietal activity after training of working memory. Nat Neurosci 7: 75-79.

O'Neill M, Brown VJ. 2007. The effect of striatal dopamine depletion and the adenosine A2A antagonist KW-6002 on reversal learning in rats. Neurobiol Learn Mem 88: 75-81.

Paine TA, Tomasiewicz HC, Zhang K, Carlezon WA Jr. 2007. Sensitivity of the five-choice serial reaction time task to the effects of various psychotropic drugs in Sprague-Dawley rats. Biol Psychiatry 62: 687-693.

Paine TA, Neve RL, Carlezon WA Jr. 2009. Attention deficits and hyperactivity following inhibition of cAMP-dependent protein kinase within the medial prefrontal cortex of rats. Neuropsychopharmacology 34: $2143-2155$

Palencia CA, Ragozzino ME. 2005. The contribution of NMDA receptors in the dorsolateral striatum to egocentric response learning. Behav Neurosci 119: 953-960.

Pierce KL, Premont RT, Lefkowitz RJ. 2002. Seven-transmembrane receptors. Nat Rev Mol Cell Biol 3: 639-650.

Preuss T. 1995. Do rats have a prefrontal cortex? The Rose-Woolsey-Acket program reconsidered. J Cogn Neurosci 7: 1-24.

Puumala T, Sirvio J. 1998. Changes in activities of dopamine and serotonin systems in the frontal cortex underlie poor choice accuracy and impulsivity of rats in an attention task. Neuroscience 83: 489-499.

Ragozzino ME, Adams S, Kesner RP. 1998. Differential involvement of the dorsal anterior cingulate and prelimbic-infralimbic areas of the rodent prefrontal cortex in spatial working memory. Behav Neurosci 112: 293-303.

Ragozzino ME, Detrick S, Kesner RP. 2002a. The effects of prelimbic and infralimbic lesions on working memory for visual objects in rats. Neurobiol Learn Mem 77: 29-43.

Ragozzino ME, Ragozzino KE, Mizumori SJ, Kesner RP. 2002b. Role of the dorsomedial striatum in behavioral flexibility for response and visual cue discrimination learning. Behav Neurosci 116: 105-115.
Redick TS, Shipstead Z, Harrison TL, Hicks KL, Fried DE, Hambrick DZ, Kane MJ, Engle RW. 2013. No evidence of intelligence improvement after working memory training: A randomized, placebo-controlled study. J Exp Psychol Gen 142: 359-379.

Rowe JB, Toni I, Josephs O, Frackowiak RS, Passingham RE. 2000. The prefrontal cortex: Response selection or maintenance within working memory? Science 288: 1656-1660.

Save E, Poucet B. 2000. Involvement of the hippocampus and associative parietal cortex in the use of proximal and distal landmarks for navigation. Behav Brain Res 109: 195-206.

Sawaguchi T, Goldman-Rakic PS. 1994. The role of D1-dopamine receptor in working memory: Local injections of dopamine antagonists into the prefrontal cortex of rhesus monkeys performing an oculomotor delayed-response task. J Neurophysiol 71: $515-528$.

Schoenbaum G, Chiba AA, Gallagher M. 1998. Orbitofrontal cortex and basolateral amygdala encode expected outcomes during learning. Nat Neurosci 1: 155-159.

Schoenbaum G, Setlow B, Nugent SL, Saddoris MP, Gallagher M. 2003. Lesions of orbitofrontal cortex and basolateral amygdala complex disrupt acquisition of odor-guided discriminations and reversals. Learn Mem 10: 129-140.

Shipstead Z, Redick TS, Engle RW. 2012. Is working memory training effective? Psychol Bull 138: 628-654.

Tang YY, Posner MI. 2009. Attention training and attention state training. Trends Cogn Sci 13: 222-227.

Tang J, Ko S, Ding HK, Qiu CS, Calejesan AA, Zhuo M. 2005. Pavlovian fear memory induced by activation in the anterior cingulate cortex. Mol Pain 1: 6.

Tronel S, Sara SJ. 2002. Mapping of olfactory memory circuits: Region specific c-fos activation after odor reward associative learning or after its retrieval. Learn Mem 9: 105-111.

Uylings HBM, Groenewegen HJ, Kolb B. 2003. Do rats have a prefrontal cortex? Behav Brain Res 146: 3-17.

Wang GW, Cai JX. 2008. Reversible disconnection of the hippocampalprelimbic cortical circuit impairs spatial learning but not passive avoidance learning in rats. Neurobiol Learn Mem 90: 365-373.

Wass C, Denman-Brice A, Rios C, Light KR, Kolata S, Smith AM, Matzel LD. 2012. Covariation of learning and "reasoning" abilities in mice: Evolutionary conservation of the operations of intelligence. J Exp Psychol Anim Behav Process 38: 109-124.

Wickens JR, Horvitz JC, Costa RM, Killcross S. 2007.

Dopaminergic mechanisms in actions and habits. J Neurosci 27: $8181-8183$.

Williams GV, Castner SA. 2006. Under the curve: Critical issues for elucidating D1 receptor function in working memory. Neuroscience 139: $263-276$.

Wilson DA. 2003. Rapid, experience-induced enhancement in odorant discrimination by anterior piriform cortex neurons. J Neurophysiol 90: $65-72$.

Received June 4, 2013; accepted in revised form August 1, 2013. 


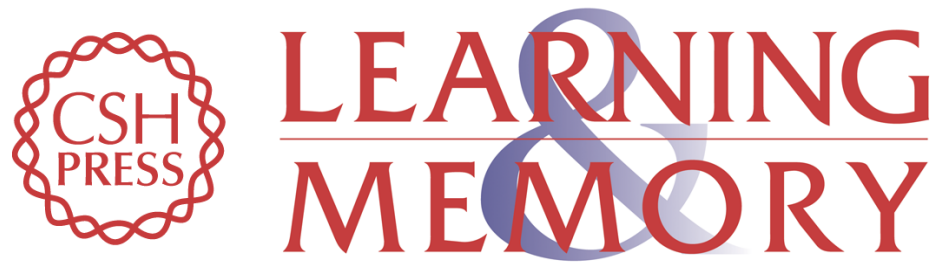

\section{Dopamine D1 sensitivity in the prefrontal cortex predicts general cognitive abilities and is modulated by working memory training}

Christopher Wass, Alessandro Pizzo, Bruno Sauce, et al.

Learn. Mem. 2013, 20:

Access the most recent version at doi:10.1101/lm.031971.113

References This article cites 91 articles, 19 of which can be accessed free at: http://learnmem.cshlp.org/content/20/11/617.full.html\#ref-list-1

Creative This article is distributed exclusively by Cold Spring Harbor Laboratory Press for the Commons License first 12 months after the full-issue publication date (see http://learnmem.cshlp.org/site/misc/terms.xhtml). After 12 months, it is available under a Creative Commons License (Attribution-NonCommercial 3.0 Unported), as described at http://creativecommons.org/licenses/by-nc/3.0/.

Email Alerting Receive free email alerts when new articles cite this article - sign up in the box at the Service top right corner of the article or click here. 